\title{
Decision process in large-scale crisis management
}

\author{
D. Kamissoko $\cdot$ P. Zaraté $\cdot$ F. Pérès
}

\begin{abstract}
This paper deals with the decision-aiding process in large-scale crisis such as natural disasters. It consists in four phases: decision context characterisation, system modelling, aggregation and integration. The elements of the context, such as crisis level, risk situation, decision-makers, problem issue are defined through the characterisation phase. At the feared event occurrence, these elements will interact on a target system. Through the model on this system, the consequences to stakes could be assessed or estimated. The presented aggregation approaches will allow taking the right decisions. The architecture of a Decision Support System is presented in the integration phase.
\end{abstract}

Keywords Decision aiding - Decision process - Crisis management · Decision Support System · Infrastructure network $\cdot$ Multicriteria $\cdot$ Natural disaster

\section{Introduction}

The good functioning of our societies relies on systems more and more complex: economy, finance, politic, infrastructure etc. None of these systems is able to function in isolation. In fact, there are interdependences among them.

D. Kamissoko $(\bowtie) \cdot F$. Pérès

LGP, University of Toulouse, Toulouse, France

e-mail: daouda.kamissoko@enit.fr

F. Pérès

e-mail: francois.peres@enit.fr

D. Kamissoko · P. Zaraté

IRIT, University of Toulouse, Toulouse, France

P. Zaraté

e-mail: pascale.zarate@irit.fr
In addition, these systems are not immune to feared events (failure, natural disaster, human error, terrorism...). This makes decision-making particularly difficult in such situation. Because every inappropriate decision could affects stakes of another system on another territory. Hence, the need to follow a decision-making process to find out compromising decisions.

The objective of this paper is to find a decision-aiding process for large-scale crisis management. Our process proposal is presented. It includes four steps: characterisation of the decision context, system modelling, multicriteria aggregation and the integration into a Decision Support System.

The proposed process is particularly suitable for natural disaster management, but it can be applied to other largescale crisis. It is usable by politics, economic decisionmakers, but also by infrastructure managers. Its particularity comes from it flexibility and the implementation of a Decision Support System.

The next section presents definitions and issues of decision aiding in the context of large-scale crisis.

\section{Definitions and issues}

Crisis is defined in many ways in the literature. It meaning is related to the discipline psychological, socio-political, technological, etc. Very often, provided definitions arise from the management theory (Pearson and Clair 1998) and rely on four aspects: causes, consequences, caution and coping (Shrivastava 1993). In this paper, a crisis is defined as a situation which manifestations might lead to an ignorance state for decision-makers; which consequences could be beyond the reaction capabilities and may affect vital stakes during a limited period of time. 
Large-scale crisis, in the context of this paper, is a crisis affecting issues scattered in independent territories in the decision-making point of view.

Crisis management is the set of decision-aiding processes implemented to contain, handle or eliminate a crisis.

Decisions may be taken with or without carrying out any decision process. But in situation such as crisis, the need of a process is emphasised by the possibility to have large negative consequences. As regard to natural disasters, crises are most often due to:

- The diversity of affected stakes;

- The geographical stench;

- The lack of prediction means.

In this kind of situation, decisions might be streamlined and analysed (Kast 1993). To overcome these difficulties and reach the set out objectives, a decision-aiding process is then needed.

The goal of the decision aiding is to provide a choice of actions among several options corresponding to one or many Decision-makers' points of view. The intention is not necessarily to seek optimal decisions. The process of decision support relies more in finding compromise.

Decision-making process issues are pointed out by Hellstom and Kvist (2001) and may arise from:

- The complexity of the problem: complexity is one of the difficulties in a decision-making process (Hellstom and Kvist 2001). It is related to decision-makers' cognitive processes;

- The uncertainty of the problem: uncertainty associated with outdoor environments;

- The multiplicity of objectives;

- The conclusions that may result from contradictory perspectives.

For large-scale crisis and specially in natural disaster analysis, we added to these issues three others: the decision-makers' emotional state instability, the consequence extend and the justification needs (Kast 1993):

- Emotional state instability In most cases, decisionmakers' emotional states are stable. But in a crisis induce from natural disaster for instance; no one can claim to be free from fear, anguish or frustration. Disaster could affect either infrastructure, or decisionmaker and his immediate family members. Decisionmaker's lucidity is then likely to be disturbed, and it seems logical and understandable that the relevance of its judgment could be questioned;

- Consequences extension Through interdependence phenomena, crisis consequences can extend beyond the initial territory;
- The need of justification The need of justification is not the same in normal decision context and crisis one. Sometime, even insignificant actions must be justified.

In a crisis context, the consequence scope is high, decisions might need justification and complexity factors are endowed. Indeed, the need of being helped seems obvious for decision-making and a relevant process has to be used. This is the aim of this paper. In the next section, we will show how decision aiding is a process.

Decision theory aims to justify, analyse and streamline actions susceptible to have negative consequences (Kast 1993). Historically, it comes from the hazard formalisation on board games. At this point in time, it touches varied and diverse fields like management, politics, economics, mathematics, psychology, risk analysis and conflict of interest situations (Kast 1993). The scope is so broad that a complete literature review is not possible (Tsoukiàs 2003).

In Simon (1977), the author was one of the first to argue that decision is not an action but a process carried out to solve problem. The author argues that decision is composed of four steps not always distinct: Intelligence, Design, Choice and Review. In Merad (2010), three phases are pointed out in the field of risk management: problem formulation, exploitation and recommendation. Decisionaiding process described by these authors focuses on the way the decision-makers collect and use information in order to understand and assist others stakeholders (Taggart and Robey 1981).

We distinguished three categories according to decision phases' succession: linear, cyclical and mixed. Linear decision-aiding process consists in sequential steps (Lavergne 1983). Cyclical decision processes are presented, as its name suggests, in form of cycle (Courbon 1992; Seguy 2008). Hybrid processes are the combination of linear and cyclic process (Simon 1977).

Nevertheless, all these decision processes must be adapted in the particular context of large-scale crisis. We propose a formalisation of this particular process.

\section{Methodology}

From Simon's point of view, decision has four main phases in the field of management: Intelligence, Design, Choice and Review. This point of view is shared by many other authors in the literature (Sprague 1980). Simon's process best suits management in industrial context than that of large-scale crisis. With regard to Tsoukiàs (2003), he presented four artefacts of a decision process: problem situation representation, problem formulation, evaluation model and final recommendation. 
Fig. 1 Decision phases

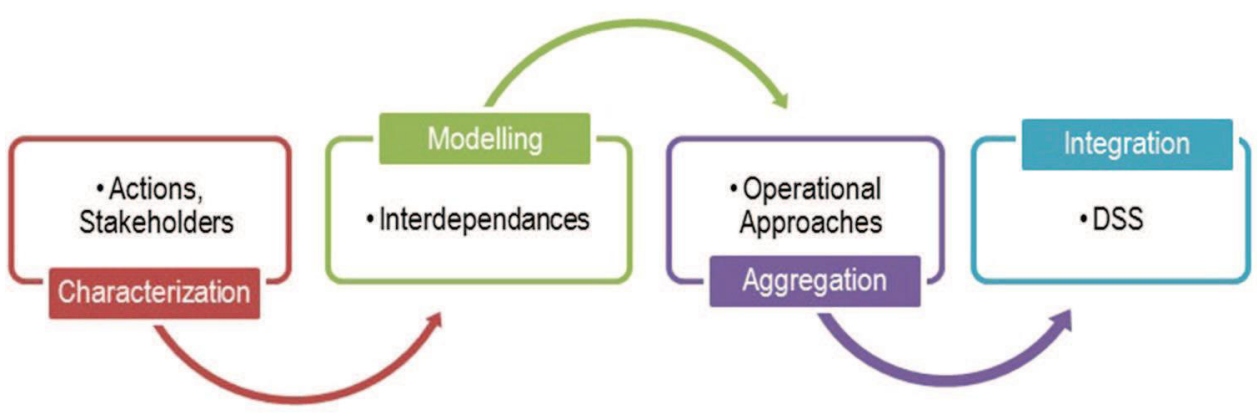

- The problem situation is represented by $P=\{A, O, S\}$ where $\mathrm{A}$ is the set of decision process participant, $\mathrm{O}$ is the set of stakes considered by decision-makers, $S$ is the set of engagement taken by decision-makers about their own stakes but also about the stakes of the other decision-makers.

- The problem formulation is represented by $\Gamma=\{\mathrm{A}, \mathrm{V}$, $\Pi\}$ where $V$ is the set of viewpoints, $\Pi$ is the decision problem.

- The evaluation model is represented by $\mathrm{M}=\{\mathrm{A}$, (D, E), $\mathrm{H}, \mathrm{U}, \mathrm{R}\}$ where $\mathrm{D}$ is the set of dimensions, $\mathrm{E}$ is the set of scales associated with each element of $\mathrm{D}, \mathrm{H}$ is the set of criteria, $\mathrm{U}$ is set of uncertainty distribution associated with $\mathrm{D}$ and/or to $\mathrm{H}, \mathrm{R}$ is the set of operators that allows the obtaining of synthetic information on elements of A.

In Tsoukiàs (2003) and Simon (1977), each phase is composed of many elements or grain. In this paper, phases are especially designed for a crisis induced by natural disasters. But they could be adapted to other situations. The main difference with the previous references is the integration phase. Indeed, crisis management is a complex task which needs the use of a Decision Support System. The process is then composed of four phases: characterisation, modelling, aggregation and integration (Fig. 1).

The originality of this model lies in phases of the decision process. It starts with the characterisation that gives an overview of the decision situation. Subsequently, a model of the object of study is proposed. Based on these two elements, decision-making is performed in the aggregation phase. Finally, these items are integrated into a DSS to facilitate the decision-making.

To validate our methodology, it was applied to a case study presented in Kamissoko (2013). The aim of this study was the evaluation of the vulnerability of the city of Lourdes against earthquake. Lourdes is a pilgrimage city since 1858 which may amplify the dramatic character of the consequences in case of the occurrence of a seism. As an illustration, the city hosted during the 150th anniversary of the Virgin apparition nearby 70,000 pilgrims per day. Among the different topics of concern, the city wishes to analyse the vulnerability of the sewage network. Through this case study, we will describe the phases of our methodology in the next sections.

\subsection{Characterisation}

The aim of characterisation is to understand the need of the decision-makers. It leads to decision characteristics called by Roy (1985) aspects of reality, or invariant. Characteristics are supposed to be sufficiently stable for every phase. Their change may orient the overall process to another direction. Our approach considers the context as a set of five components:

$\mathrm{C}=\{\mathrm{CL}, \mathrm{RS}, \mathrm{DM}, \mathrm{D}, \mathrm{DP}\}$

where CL is the crisis level, RS the risk situation, DM the decision-makers, D decisions, DP the decision problems. The problem formulation in our point of view may integrate crisis level, risk situation and decision level. These elements have not direct impact on the decision model, but they could change the decision-maker's behaviour and indirectly the final decision. These components are presented in the following.

\subsubsection{Decision-makers identification}

One of the characterisation step issues is to answer the question: who is going to be helped by the decision or who is going to take decisions? Decision-makers are also named actors or stakeholders. The following definition is adopted in this paper.

Definition 1 Decision-maker is individual or individual group of which by their value system, whether at first degree because of their intentions or second degree by the way they involve those of others, directly or indirectly influences decision (Roy 1985).

Any decision aiding should start by their identification (Baker et al. 2001). By way of illustration, Table 1 shows Martel's identification approach by decision-makers' participations and influences quoted by Merad (2010). 
Table 1 Martel's decision-maker identification

\begin{tabular}{lll}
\hline & $\begin{array}{l}\text { Directly } \\
\text { involved }\end{array}$ & $\begin{array}{l}\text { Indirectly } \\
\text { involved }\end{array}$ \\
\hline $\begin{array}{l}\text { Influence the problem } \\
\text { Affected by the problem }\end{array}$ & $\begin{array}{l}\text { Fiduciaries } \\
\text { Concerned and } \\
\text { active }\end{array}$ & $\begin{array}{l}\text { Invisibles } \\
\text { Concerned and } \\
\text { passive }\end{array}$ \\
$\begin{array}{l}\text { Influence and is affected by } \\
\text { the problem }\end{array}$ & Traditional & Behind curtains \\
\hline
\end{tabular}

Zaraté (2013) described six types of actors for Decision Support Design: initiator, analyst, developer, validation team, user, and decision-maker. This identification is less applicable to large-scale crisis. Indeed, one decision-maker might influence and be affected. Then, identification by implication and the way to use the DSS seems more relevant. Decision-makers can be classified according to several points of view. Will be distinguished in particular:

- The geographical levels related to the magnitude of the crisis

- International level;

- National level;

- Regional level;

- Local level.

- The hierarchical levels in the Organisation

- Infrastructure manager;

- Local operator.

- The type of decision

- Individual;

- Collective.

- The role in relation to the event

- Victim;

- Rescue services;

- Coordinator;

- Analyst.

This categorisation will allow designing the DSS according the use made by every DM. For instance, in the case study was considered The citizen, the infrastructure manager, and the regional. Then, the functionalities are designed further according the need of these DMs. The next component is the crisis level in the following.

\subsubsection{Crisis level}

Crisis-level analysis is investigated by many institutions and governments. The FEMA (Federal Emergency Management Agency) pointed out four levels in a crisis management: preparedness, mitigation, emergency response and recovery. Harding et al. (2001) identified three levels: pre-crisis, crisis and post crisis. These phases are too simplistic especially in large-scale crisis. From our point of view, a crisis is made up of the following phases (Fig. 2):

- Investigation Identification of the feared events and the stakes. This is the phase of ignorance which aims to identify risks;

- Awareness In this phase, the nature of the risks is known, stakeholders are aware of the situation, and the cognitive process aiming at assessing the risks is launched;

- Simulation Evaluation of the different scenarios through reality-based models;

- Warning Appearance of the feared events signs;

- Event Occurrence of the feared events;

- Replication The event is over but the risk of recurrence is high. (earthquake aftershocks for instance);

- Post-event The crisis is over, but it remains to rebuild and repair damages;

- Stability Feedback formalisation for analysing the appropriateness of the deployed strategies.

The identified DMs have to determine in which level is the analysis. This determination will allow fixing the actions' scope for the decision aiding. In the case study, we focused on the simulation phase. In fact, this phase offers the largest scope.

For each crisis level, it is necessary to evaluate the risk situation. The next section presents then the risk situation.

\subsubsection{Risk situation}

The risk situation depends on available information and knowledge. In Merad (2010), the authors have identified three situations of risk: total uncertainty (cube 1 in Fig. 3incomplete information and knowledge), risk (cube 2 in Fig. 3-full information, exhaustive knowledge), uncertainty (cube 2 in Fig. 3-between both situations, with subjective probabilities). Figure 3 characterises the crisis level according to the risk situation pointed out by Merad (2010) for the case study. Based on crisis level, it shows that phases of stability, post-event crisis and simulation are in a risk situation; phases of warning in an uncertain situation; phases of replication, awareness, and investigation in a total uncertain situation.

This representation will allow the assessment of action according criteria. For instance, for the case study, the simulation is in risk situation. That means that we face complete information and knowledge more or less exhaustive. In such situation, we have modelled to assessment actions. The reader is invited to see Kamissoko et al. (2013) for more information about the model. 
Fig. 2 Crisis level

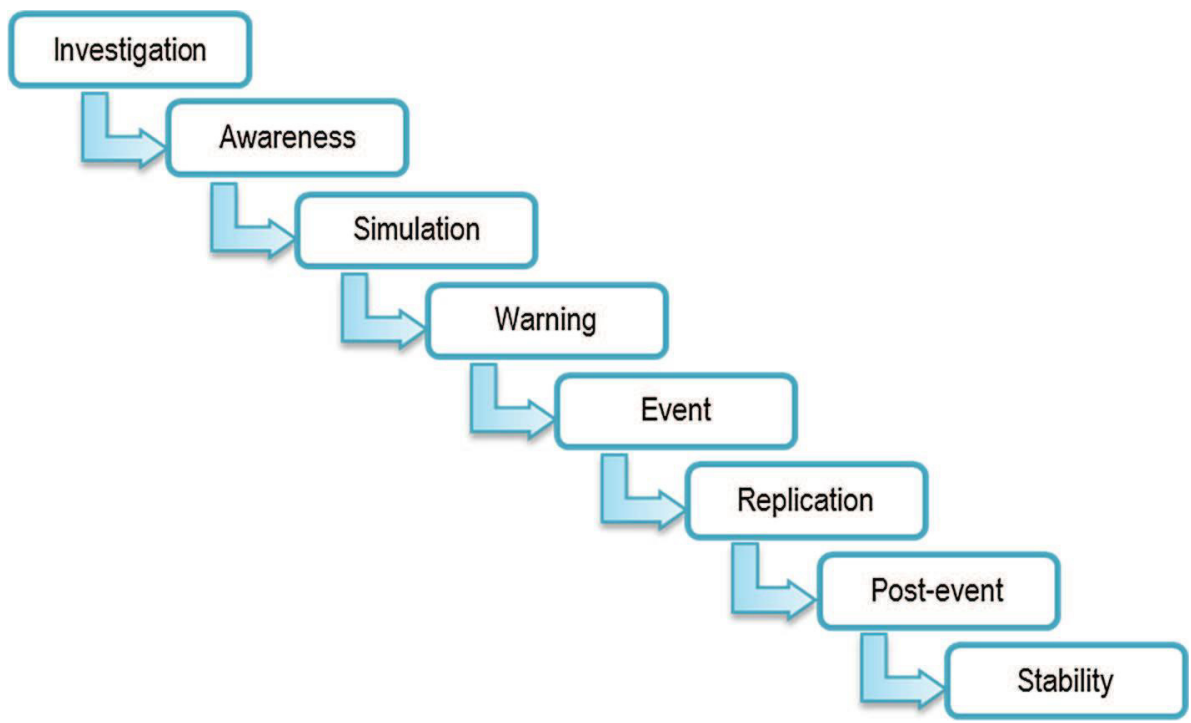

Fig. 3 Crisis situation inspired from Merad (2010)

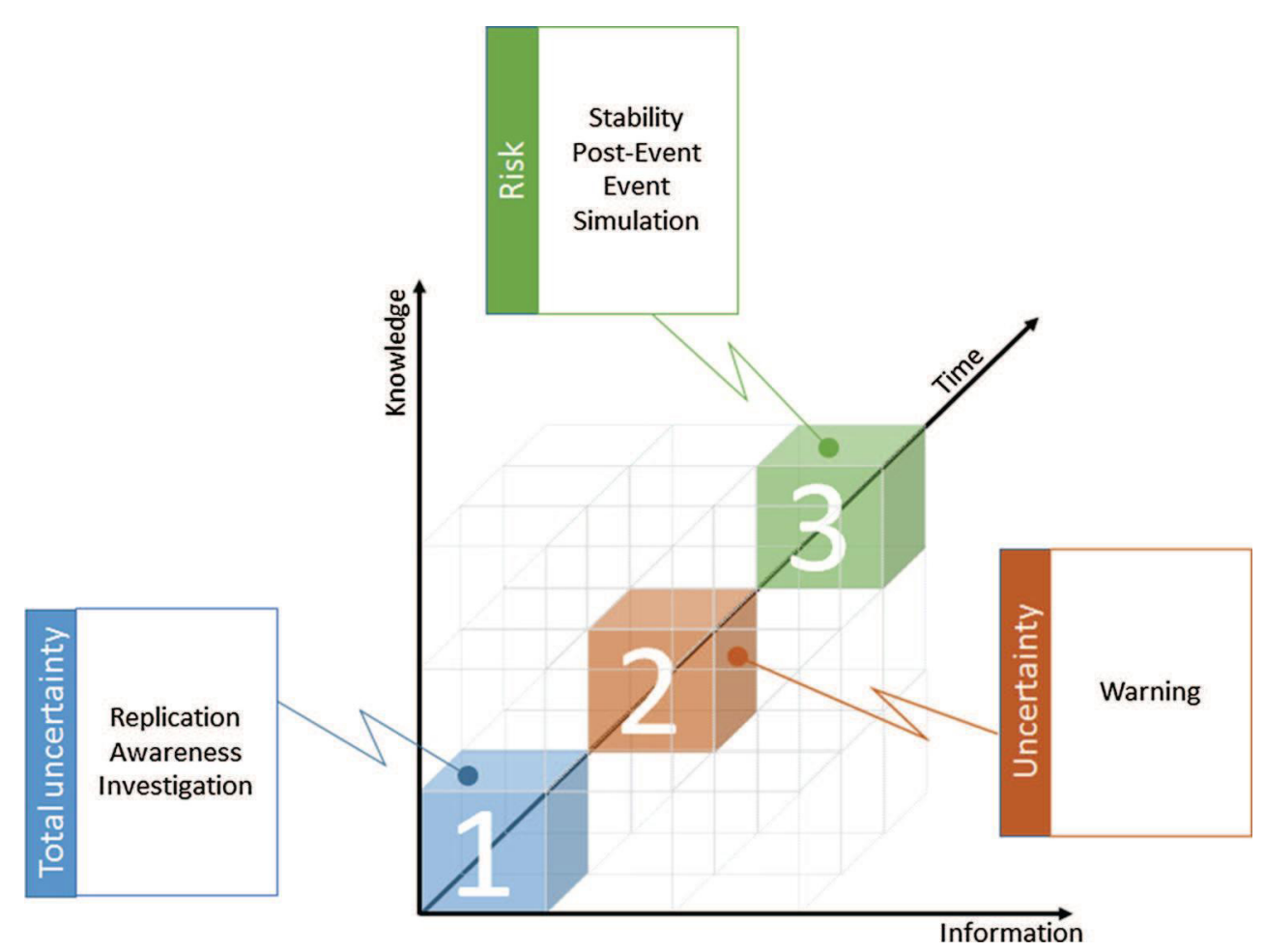

The next step is to determine the set of decision. This is the aim of the next section.

\subsubsection{Decisions}

Decision-makers are likely to make arrangements and take decisions to solve identified problems. Decision is also called action. Simon distinguishes two types of decision.
The first is programed and repetitive, the second is unscheduled, unusual and unstructured. From this standpoint, the decision-making in a crisis context consists obviously in taking unscheduled decisions. In large-scale crisis, decision numbers directly proportional to the number of involved components being high, they should be defined by a description instead of an exhaustive list. Furthermore, the environment of a crisis is changing. Decisions are then 
Table 2 Relational preference systems

\begin{tabular}{llll}
\hline Phases & \multicolumn{2}{l}{ Decision-maker } \\
\cline { 2 - 4 } & $\begin{array}{l}\text { Local } \\
\text { operator }\end{array}$ & $\begin{array}{l}\text { Infrastructure } \\
\text { manager }\end{array}$ & $\begin{array}{l}\text { International, } \\
\text { National }\end{array}$ \\
\hline Investigation & I,P,Q & R,P,Q,I & R,S \\
$\begin{array}{l}\text { The awareness of the } \\
\text { situation }\end{array}$ & I,P,Q & I,> & R,S \\
Simulation & & & \\
Warming & I,P,Q & I, $>$ & R,S \\
Crisis & I,P,Q & I, $>$ & R,S \\
Replication & R, I,> & R,S & R,S \\
Post-event & R, I,> & R,S & R,S \\
Stability & I,P,Q & R,I,S & R,S \\
\hline
\end{tabular}

becoming progressive. They are also fragmented in as much as the results of the decision process involve combinations of several elements of the actions' set.

In the case study, decisions are categorised according six categories:

- Action on network components Action on component may be changing some of their structural parameter; reliability etc. It can also consist in adding or removing component; Building new roads and airfields, and increasing the reliability of a power plant are examples of action on network component.

- Action on flows Action on flow consists in changing its speed, reliability, resistance and circulation law. Adaptation of this law can contribute to streamlining of the entire network. This is especially what happens on the power grid, where electricity is supplied to vital structures in case of power outage;

- Action on factors For example, increasing hospital autonomy by providing generators or additional beds;

- Action on stakes The evacuation of an area, the riser of a transformer;

- Action on interdependences Interdependence might be a cause of cascading failure, when one component failure impacts on other components' failures. Acting on these interdependencies can help to significantly reduce network's vulnerability.

- Action on feared event Feared event is characterised among other by its propagation speed. Decision-maker could take some measures to reduce it.

These actions will be aggregated according DMs' preference system in the next.

\subsubsection{Preferences systems}

Actions cannot be compared one by one because of their generic definition. To accomplish this comparison, decision-
Table 3 Decision-making criteria

\begin{tabular}{|c|c|}
\hline Consequences & Indicators \\
\hline System & $\begin{array}{l}\text { Failure cost, flux losses, flux congestion, } \\
\text { reparation, interruption in communication and } \\
\text { transportation }\end{array}$ \\
\hline Human & $\begin{array}{l}\text { Number of death, number of injured, number of } \\
\text { traumatised }\end{array}$ \\
\hline Environment & Affected ecological systems, , affected species \\
\hline Economy & $\begin{array}{l}\text { Employment losses, insurance, cost, } \\
\text { reconstruction }\end{array}$ \\
\hline Patrimony & Branding \\
\hline Legislation & Norms \\
\hline Politic & Political stability \\
\hline \multicolumn{2}{|l|}{ Education } \\
\hline Comfort & Indoor temperature \\
\hline Cognitive factors & $\begin{array}{l}\text { Risk acceptation, risk knowledge, change } \\
\text { management, population training }\end{array}$ \\
\hline \multicolumn{2}{|l|}{ Cultural factors } \\
\hline \multicolumn{2}{|l|}{$\begin{array}{l}\text { Organisation/ } \\
\text { institutions }\end{array}$} \\
\hline Security & Increase in crimes \\
\hline
\end{tabular}

makers, or the analyst judging by their names, must develop a relational preference system. This system reflects diverse views that can be opposed, or even contradictory. Thus, the system must tolerate ambiguity, contradiction, and learning wherever possible (Roy 1985). Preference systems are also called "approach and the dominant culture" (Merad 2010). They are set of beliefs, attitudes and assumptions shared by a group as a result of past experiences (Merad 2010). We have determined the preference system for decision-makers in Table 2.

There are four basic preference situations: I (indifference), $\mathrm{P}$ (strict preference), Q (low preference) and $\mathrm{R}$ (incomparability). The totality of a decision-maker's preference can be grouped into the fundamental relational system of preference, or in the grouped relational system of preference (Roy 1985), including the outranking relation (S) the presumption of preference $(\mathrm{J})$ general preference $(>)$, non preference $(\sim)$, K preference $(K)$.

Table 2 illustrates systems accepting and refusing incomparability: (I, >), (I, Q, P), (I, R, >), (R, S), (R, I, S). Decision-makers of category 1 (Local operator) admit incomparability in critical phases. This is due to the fact that before these phases data are available at the local level. Risk for stakes allows taking time for the analysis. This situation is similar for the second class (Infrastructure manager), except the investigation phase - where data are less available. However, in line with regulatory requirements, and facing potential communication and collaboration process, decision-maker has to accept the incomparability at the international and national level. 
Table 2 helps to focus on the aggregation method category. For instance, in the case study, for the simulation, we will consider the ELECTRE methods. Every decision is evaluated according consequences in the next section.

\subsubsection{Consequences}

The consequence could be called indicators, impacts, damage or prejudice. They are defined as a progressive effect of system failure through time, on users (Benoît and Luviano 2009). The term damage alludes to material damage, loss refers to human lives (Reghezza 2006) and prejudice concerns people damages (Leone 2007). Generally, an action has several consequences (Nafi and Werey 2010). We have identified 13 categories of consequences induced by large-scale crisis: These are presented in Table 3 .

Table 3 shows the wide variety of crisis consequences. Some of them can be determined by a model presented in the modelling section. Others will be determined by experts' judgments. Potential actions are evaluated according to some modes presented in the next section. For instance, the loss of flow or the number of affected people can be determined by the model. On the contrary, the political effect has to be determined by expert judgment. In the case study, indicators related to the system itself were assessed according our model presented in Kamissoko et al. (2013). The others are estimated according DMs' judgment. The evaluation approach is presented in the following.

\subsubsection{Evaluation mode}

Decision-makers must evaluate potential decision according to the consequences. The evaluation can be performed by one of the following modes. These modes represent the granularity.

- Evaluating actions' scenarios after feared event scenarios;

- Evaluating actions' scenarios after the elements of feared event scenarios;

- Evaluating elements of actions' scenarios after elements of feared event scenarios.

In the case study, because of the fact that the study is in the simulation phase, we have adopted the first evaluation mode.

The model implemented in the simulation is presented in the following.

\subsection{Modelling}

The decision-aiding process is based on models of the identified systems and events. The role of the modelling is to understand the dynamic. According to the problem, many kinds of representations can be used. Mainly, there are analytical (decision elements description by functions or values) and graphical models (decision tree, graph, arrays etc.).

As regard to infrastructure network, a modelling approach is presented in Kamissoko et al. (2013). In this approach, network is modelled by graphs with interdependences between nodes and edges. From this model, a vulnerability assessment is proposed.

The aggregation of the assessed and estimated consequences is presented in the following.

\subsection{Muticriteria aggregation}

Criteria are derived from actions' consequences (Nafi and Werey 2010) and allow their assessment. They represent consequences function for which one seeks to determine the maximum or the minimum (Kast 1993). In this paper, the main criterion in the decision point of view is as follows:

- Assessed criteria Vulnerability, resilience, robustness etc.;

- Not assessed Environment, economy, politic, etc.

In the literature, several decision-aiding methods for aggregation can be found. With regard to Multicriteria Decision Aiding, the difference resides in the aggregation procedures (Merad 2010). Methods of multicriteria decision aiding can be divided into three families, called operational approaches for aggregating performance in Roy and Bouyssou (1993) and Kast 1993): single synthesis criterion, outranking, local interactive judgment with iterations try-error. Zopounidis and Doumpos (2002) also identified three families: The classical approaches, outranking, and utility functions. Baker et al. (2001) argue that criteria should be limited in number, complete, including goals, significant, operational, able to discriminate actions and support comparison of all actions performance. To choose an adapted method, seven questions are proposed in Merad (2010):

- Stakeholders in the decision, are they numerous or not?

- How to think or what cognition procedure is used by decision-makers?

- What is the problem referring to?

- What information is available?

- What level of compensation does the decision-maker seek?

- What are the basic assumptions available?

- Is there any software that takes up the principles?

Multiattribute methods allow solving programs that provide satisfactory solutions of various criteria on the basis of linear combination or nonlinear functions. 
Table 4 Aggregation methods

\begin{tabular}{llll}
\hline Phase & Problem & $\begin{array}{l}\text { Mean } \\
\text { problem }\end{array}$ & Method \\
\hline $\begin{array}{l}\text { Investigation } \\
\begin{array}{c}\text { The awareness } \\
\text { of the situation }\end{array}\end{array}$ & $\mathrm{P}_{\delta} \mathrm{P}_{\alpha}, \mathrm{P}_{\beta}, \mathrm{P}_{\omega}$ & $\begin{array}{l}\text { Sorting } \\
\text { Ranking }\end{array}$ & $\begin{array}{l}\text { ELECTRE TRI } \\
\text { ELECTRE IV }\end{array}$ \\
$\begin{array}{l}\text { Simulation } \\
\text { Warning }\end{array}$ & $\mathrm{P}_{\delta}, \mathrm{P}_{\omega}$ & Ranking & ELECTRE IV \\
Crisis & $\mathrm{P}_{\delta}, \mathrm{P}_{\alpha}$ & Choice & ELECTRE IS \\
Replication & $\mathrm{P}_{\delta}, \mathrm{P}_{\alpha}, \mathrm{P}_{\beta}, \mathrm{P}_{\gamma}, \mathrm{P}_{\kappa}$ & Choice & ELECTRE IS \\
Post-event & $\mathrm{P}_{\delta}, \mathrm{P}_{\alpha}, \mathrm{P}_{\beta}, \mathrm{P}_{\gamma}, \mathrm{P}_{\kappa}$ & Choice & ELECTRE IS \\
Stability & $\mathrm{P}_{\delta}, \mathrm{P}_{\alpha}, \mathrm{P}_{\beta}, \mathrm{P}_{\gamma}, \mathrm{P}_{\omega}, \mathrm{P}_{\kappa}$ & Ranking & ELECTRE IV \\
\hline & $\mathrm{P}_{\delta}, \mathrm{P}_{\kappa}, \mathrm{P}_{\omega}$ & Sorting & ELECTRE TRI \\
\hline
\end{tabular}

Outranking methods do not follow the axiom that all consequences are comparable. They therefore agree to the incomparability (Kast 1993; Merad 2010). For these reasons, outranking methods are chosen for the aggregation. In this area, two methods suit the context of this paper: ELECTRE and PROMETHEE. In ELECTRE methods, the procedure aims to reduce the size of non-dominated sets of alternatives (kernel). The idea is that an alternative can be eliminated if it is dominated by other alternatives to a specific degree. The procedure is the first one to seek to aggregate the preferences instead of the performances (Roy 1968). PROMETHEE is based on the same principles as ELECTRE and introduces six functions to describe the Decision-Maker preferences along each criterion. This procedure provides a partial order of the alternatives using incoming and outgoing flows (Mareschal et al. 1984).

We have rejected PROMETHEE because of the fact that in the context of this paper decisions is defined in a generic way so considered as infinite according to the number of components. In fact, PROMETHEE method is defined for finite actions (Behzadian et al. 2010). Otherwise, our analysis shows many problems in large-scale crisis. This is not the case for PROMETHEE which is mainly for ranking problem (Behzadian et al. 2010). For these reasons, we have rejected PROMETHEE and chosen the ELECTRE methods. Such methods have many variants. We used the proposition of Maystre et al. (1994) to select the appropriate method for each phase. The result of this analysis is given in the Table 4 (Fig. 4).

Table 4 shows for each crisis level the dominant problem and the aggregation method: sorting $\left(\mathrm{P}_{\beta}\right)$, which corresponds to a form of assignment to predefined categories;

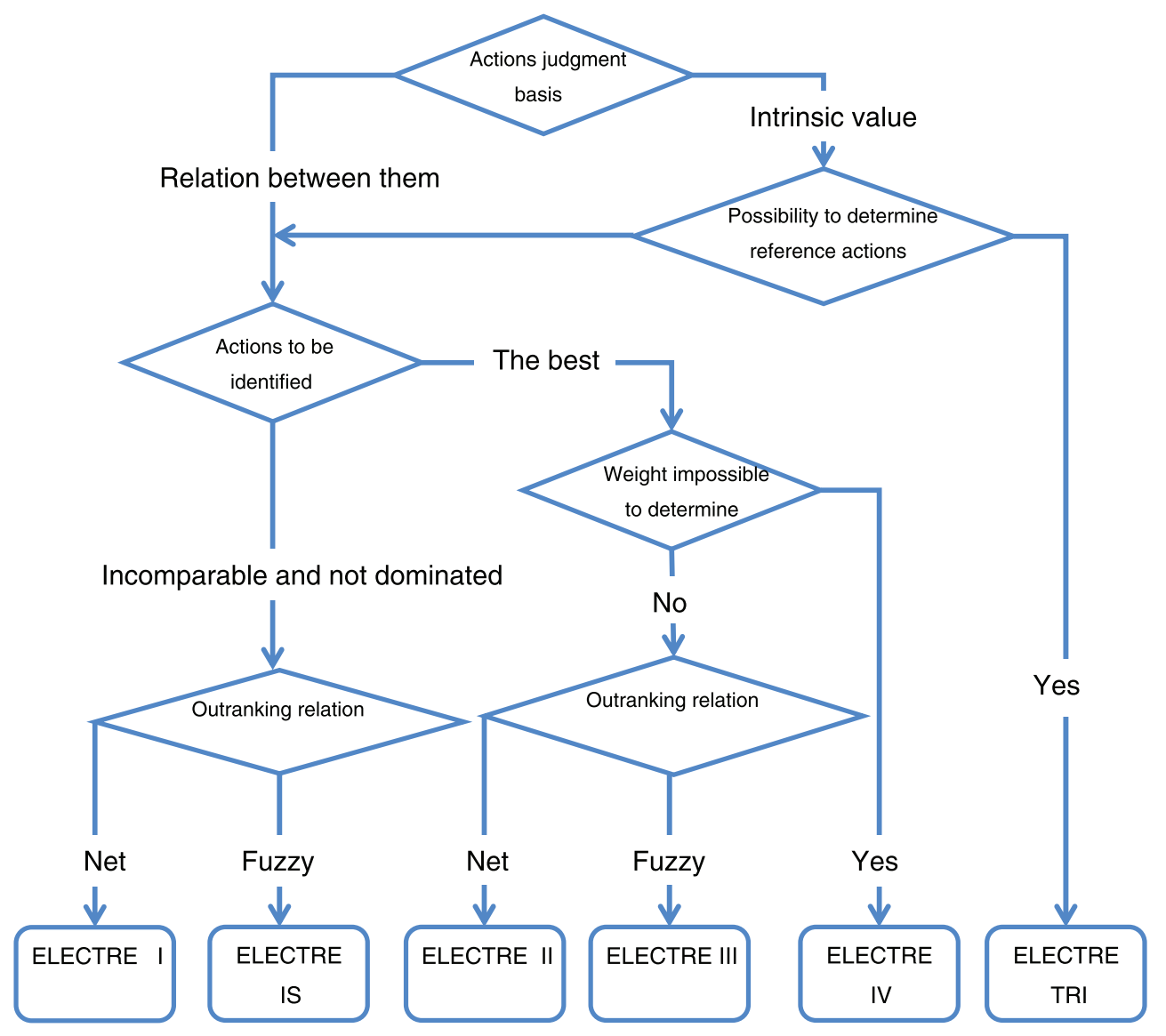

Fig. 4 ELECTRE methods by Maystre et al. (1994) 
Fig. 5 Decision Support System structure by Sprague (1980)

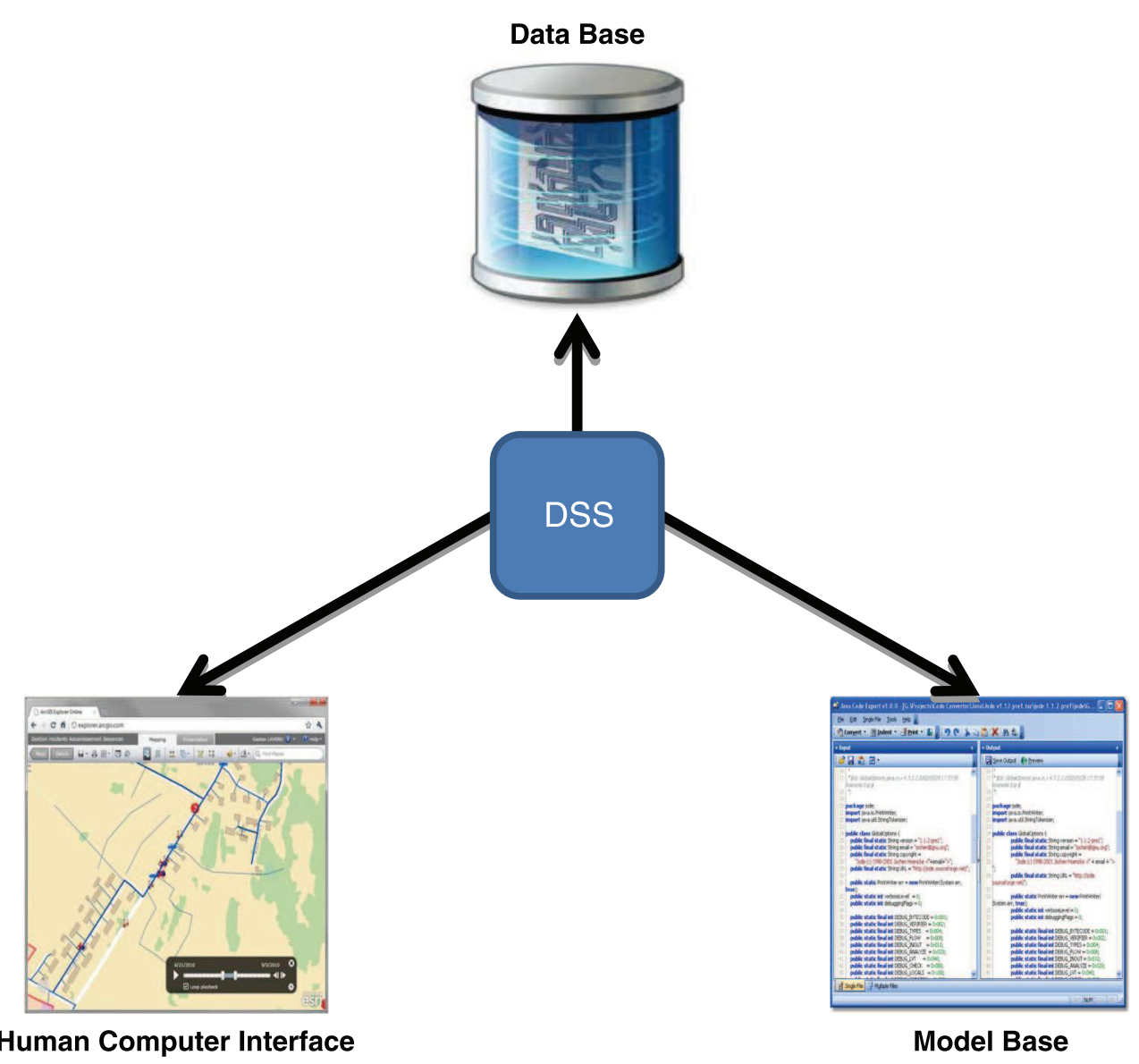

rank $\left(\mathrm{P}_{\gamma}\right)$, which takes the form of a ranking actions; and description $\left(\mathrm{P}_{\sigma}\right)$ for describing and structuring. $\mathrm{P}_{\sigma}$ precedes other problems (Merad 2011). In natural disaster context, we pointed out two other problems: acceptance and change management $\left(\mathrm{P}_{\omega}\right)$, and planning problem $\left(\mathrm{P}_{\mathrm{\kappa}}\right)$ (Kamissoko 2013).

Choice problem is dominant in the level of warning, crisis and replication phase. This results from the fact that in these situations the most important is to determine best decisions among the potential ones. Because of data imperfection, ELECTRE IS is recommended. ELECTRE IS is a further version of ELECTRE IV which takes into account the notion of veto threshold. This method is the current version of choice problem (Figueira et al. 2005).

Sorting problem is dominant in the phases of investigation and stability. In fact, during these phases, the main objective is to categorise decisions. For this reason, ELECTRE TRI is proposed.

Ranking problem is encountered and predominates in the phases of awareness, simulation and post-event. In these phases, it is more relevant for the users to rank decisions in order to select best ones later. For this reason, we use ELECTRE IV. This method is the only ELECTRE method which does not make use of the relative criteria importance coefficients (Figueira et al. 2005).

The aggregation methods selected in this phase are implemented in a DSS in the next phase.

\subsection{Integration}

The integration is the set of operations to speed up the process using a Decision Support System. The architecture adopted in this paper for the Decision Support System design is those proposed by Sprague (1980). This architecture is composed of three parts: human computer interface, data base and model base. (Wallace and Balogh 1985) added to these parts a data analysis capability. In our approach, this module is managed by the database management system. In some situations, a spatial Decision Support System can be endowed with prominent spatial components (Snediker et al. 2008) (Fig. 5).

Figure 6 represents the architecture proposed by Sprague (1980). Database is endowed with data analysis capability performed by a Data Base Management System (DBMS). The model base is related to a normative model implemented in a Model Based Management System 
Fig. 6 Results

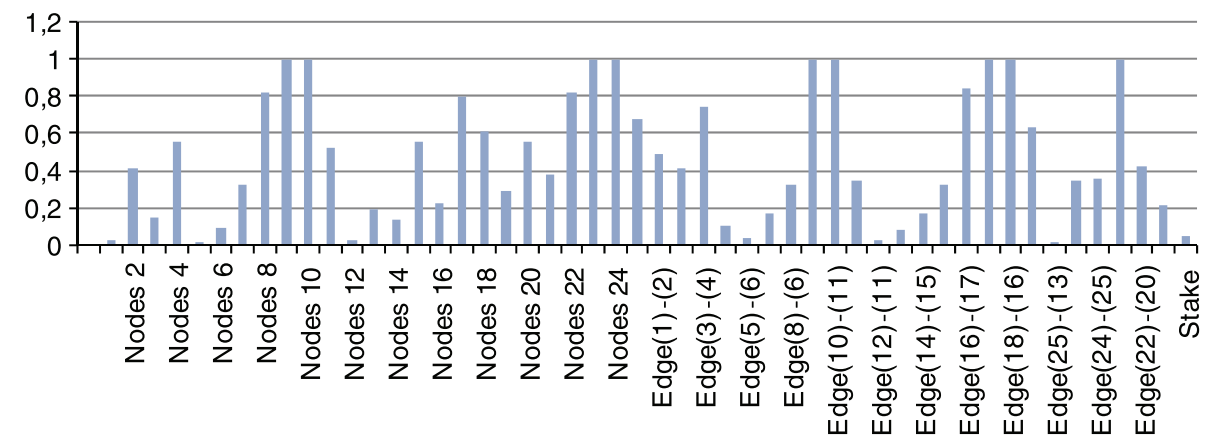

(MDBS): it allows giving unobtrusive solutions and evaluating trade-offs between actions, and possibly providing those to be implemented. The Human Computer Interface is related to a Dialogue Management System.

A classical architecture has been adopted for the DSS. The originality of our approach is the implementation of a vulnerability model presented in Kamissoko et al. (2013).

A simulation was performed for the case study in our system. The below figure shows a display of the vulnerable component.

With our methodology, we helped the city of Lourdes to have an overview of the vulnerability of it sewage network. The main action which emerged from the analysis is the evacuation of the population. The city is then considering building new evacuation zones.

\section{Conclusion}

Natural disasters have stricken populations everywhere in the word in the past years. For example in 2004, the Indian Ocean tsunami caused 220,000 deaths. Next, the cyclone Nargis in Myanmar made 138,373 deaths in 2008. In the same year, an earthquake in China killed 87,449 people. Two years later in 2010 , a total of 230,000 people were killed by an earthquake of 7.0 in Haiti. More recently, in March 2011, a tsunami in Japan made 18,079 deaths. These few examples show the devastating character of natural disasters for human being which generally leads to largescale crisis.

The objective of the paper was to face this kind of situation by providing a decision-aiding process. We then answered the following questions:

- What are the elements of the context to be taken into account for the decision aiding?

- Who could take decision?

- What problems could be faced?

- How to take into account the effects of systems on decisions?

- What are the consequences?
- What aggregation method to use in what phase?

- How could a Decision Support System be useful?

The approach is separated in four steps. In the characterisation phase, the interacting elements of the process are identified. Decisions, decisions-makers and decision problems are the pointed out. In the next step, the modelling will allows the assessment of the feared event effect on stakes through some systems. Consequences are assessed from the model or estimated by decision-makers. These are then aggregated to find out compromising solutions using some aggregation methods. If needed, decision-makers can use a Decision Support System in the integration phase.

As we have shown, the application of a decision process needs the implementation of a Decision Support System.

\section{References}

Baker D, Bridges D, Hunter R, Johnson G (2001) Guidebook to decision-making methods. Department of Energy, USA

Behzadian M, Kazemzadeh RB, Albadvi A, Aghdasi M (2010) PROMETHEE: a comprehensive literature review on methodologies and applications. Eur J Oper Res 200(1):198-215

Benoît R, Luviano M (2009) Réduire la Vulnérabilité des infrastructures essentielles. TEC \& DOC, Lavoisier

Courbon JC (1992) Processus de décision et aide à la décision. Econ Soc XVI(12):1455-1476

Figueira J, Mousseau V, Roy B (2005) ELECTRE methods. Multiple criteria decision analysis: state of the art surveys. Springer, New York, pp 133-153

Harding TW, Romerio F, Frischknecht C, Wagner J-J (2001) Management des risques majeurs: des disciplines à l'interdisciplinarité. Programme plurifacultaire du Rectorat Management des Risques Majeurs

Hellstom P, Kvist T (2001) Evaluation of decision support modules and human interfaces using the TopSim simulator. In: Presented at the 5th world congress on railway research (WCRR 2001), Cologne, Germany

Kamissoko D (2013) Decision support for infrastructure network vulnerability assessment in natural disaster crisis situations. Doctorate, University of Toulouse, University of Toulouse 1 Capitole

Kamissoko D, Pérès F, Zaraté P (2013) Technological networks robustness and resilience assessment. In: Presented at the 5th 
international conference on industrial engineering and systems management, Rabat, Morocco

Kast R (1993) La théorie de la décision. La Découverte

Lavergne J-P (1983) La décision: psychologie et méthodologie. Les éditions E.S.F, Paris

Leone F (2007) Caractérisation des vulnérabilités aux catastrophes « naturelles » : contribution à une évaluation géographique multirisque (mouvements de terrain, séismes, tsunamis, éruptions volcaniques, cyclones). Habilitation à Diriger des Recherches, Université Paul Valery, Montpellier III, Montpellier

Mareschal B, Brans JP, Vincke P (1984) Prométhée: a new family of outranking methods in multicriteria analysis. ULB-Universite Libre de Bruxelles, ULB Institutional Repository 2013/9305

Maystre LY, Pictet J, Simos J (1994) Méthodes multicritères ELECTRE: description, conseils pratiques et cas d'application à la gestion environnementale. PPUR presses polytechniques

Merad M (2010) Aide à la décision et expertise en gestion des risques. Tec \& Doc, Lavoisier

Merad M (2011) Processus d'aide à la décision en gestion des risques. Université de Paris Dauphine, Paris

Nafi A, Werey C (2010) Aide à la décision multicritère: introduction aux méthodes d'analyse multicritère de type ELECTRE. ENGEES Ingénierie Financière

Pearson CM, Clair JA (1998) Reframing crisis management. Acad Manage Rev 23(1):59-76

Reghezza M (2006) Réflexions autour de la vulnérabilité métropolitaine : la métropole parisienne face au risque de crue centennale. Université Paris X, Nanterre

Roy B (1968) Classement et choix en présence de points de vue multiples. RAIRO 2(V1):57-75
Roy B (1985) Méthodologie multicritère d'aide à la décision. Économica, Paris

Roy B, Bouyssou D (1993) Aide multicritère à la décision méthodes et cas. Économica, Paris

Seguy A (2008) Décision collaborative dans les systèmes distribués: Application à la e-maintenance. University of Toulouse, Toulouse

Shrivastava P (1993) Crisis theory/practice: towards a sustainable future. Org Environ 7(1):23-42

Simon HA (1977) The new science of management decision. Prentice-Hall, New Jersey

Snediker DE, Murray AT, Matisziw TC (2008) Decision support for network disruption mitigation. Decis Support Syst 44(4): 954-969

Sprague RH (1980) A framework for the development of decision support systems. MIS Q 4(4):1-26

Taggart W, Robey D (1981) Minds and managers: on the dual nature of human information processing and management. Acad Manag Rev 6(2):187

Tsoukiàs A (2003) De la théorie de la décision à l'aide à la décision

Wallace WA, Balogh FD (1985) Decision support systems for disaster management. Pub Admin Rev 45:134-146

Zaraté P (2013) Tools for collaborative decision-making. Wiley. http://www.wiley.com/

Zopounidis C, Doumpos M (2002) Multicriteria classification and sorting methods: a literature review. Eur J Oper Res 138(2): $229-246$ 